\title{
ON THE ADDICTIVE POWER OF GABAPENTINOIDS: A MINI-REVIEW
}

\author{
Udo Bonnet $^{1,2}$, Emily-Lisa Richter ${ }^{1}$, Katrin Isbruch ${ }^{1}$ \& Norbert Scherbaum ${ }^{2}$ \\ ${ }^{I}$ Department of Psychiatry, Psychotherapy and Psychosomatic Medicine, Evangelisches Krankenhaus Castrop-Rauxel, \\ Academic Teaching Hospital of the University of Duisburg-Essen, Castrop-Rauxel, Germany \\ ${ }^{2}$ LVR-Hospital Essen, Department of Psychiatry and Psychotherapy, Faculty of Medicine, \\ University of Duisburg-Essen, Essen, Germany
}

received: 26.10 .2017

revised: 27.3.2018;

accepted: 2.5 .2018

\section{SUMMARY}

The gabapentinoids gabapentin and pregabalin have been related to addiction citing pharmacovigilance data, some case presentations and increasing reports mainly from methadone maintenance treatment programs or emergency medicine. Most of these reports were based on patients with another current or previous substance use disorder (SUD). According to the ICD-10 dependence criteria, physical dependence (withdrawal symptoms, tolerance) was reported most frequently alongside regular use of gabapentinoids. Far less patients showed key symptoms of behavioral dependence (craving, loss of control, or addictive behavior). Through a literature review, we found 2 and 13 case reports about gabapentionoid-seeking behavior or craving for gabapentin and pregabalin, respectively. Those patients without a history of another SUD, but being behaviorally dependent on gabapentinoids, deemed more appropriate to reflect the true addictive power of these drugs. We found solely 4 such cases, all referring to pregabalin and none for gabapentin. Taking into account that gabapentinoids have become widely distributed and easily obtainable via the internet or black-markets, one would expect many more of these cases, if gabapentinoids had considerable addictive power. Moreover, we are not aware of any patient who sought detoxification treatment owing to the misuse of gabapentinoids. Unlike for traditional psychoactive drugs, there is only very scarce evidence for gabapentinoids to be misused in a long-term manner and to be rewarding and reinforcing in animal experiments. Further, we assessed the hazardous potential of gabapentin and pregabalin in relation to that of traditional substances of abuse. Altogether, we support the view that gabapentinoids are quite rarely addictive in the general population. In patients with a history of SUD, however, gabapentinoids (notably pregabalin) should avoided or, if thought to be beneficial, administered with caution by using a strict prescription and therapy monitoring.

Key words: gabapentin - pregabalin - addiction - abuse - dependence - wanting - liking - ranking - adverse effects

$* * * * *$

\section{INTRODUCTION}

In the past ten years, there have been increasing reports linking gabapentin and pregabalin to abuse and dependence, life-threatening intoxications and death (Schifano et al. 2011, Prescrire Int 2012, Häkkinen et al. 2014, Ongley et al. 2014, Elliott et al. 2016, Mersfelder \& Nichols 2016, Smith et al. 2016, Schjerning et al. 2016a). Therefore, we have undertaken this minireview to propose a first approach to compare their hazardous potential with that of traditional psychoactive substances.

\section{PHARMACOLOGY OF GABAPENTINOIDS}

Pregabalin and gabapentin are approved pharmaceuticals for the treatment of some epileptic and pain disorders, and pregabalin also for generalized anxiety disorder (Bockabader et al. 2010, Calandre et al. 2016). Pharmacologically, both drugs are very closely related (Bockbader et al. 2010, Calandre et al. 2016). Therefore, gabapentin and pregabalin can be placed in own group of gabapentinoids (Rogawski \& Bazil 2008). They are 3-substituted derivatives of the neurotransmitter $\gamma$-aminobutyric acid (GABA) and known inhibitors of $\alpha 2 \delta$-subunit-containing voltage-dependent calcium channels (VGCC). These special VGCCs are predominantly located in presynaptic membranes, and gabapentinoids were shown to restrain stimulus-dependent synaptic transmitter release, chiefly the excitatory transmitter glutamate and norepinephrine, but not dopamine (Dooley et al. 2000, Bockbader et al. 2010, Rogawski \& Bazil 2008). There by, gabapentinoids may act against aberrant neuronal excitation and, possibly, also against sensitization (Eroglu et al. 2009). Additionally, therapeutic doses of gabapentinoids are dose dependently associated with a modest increase of the extracellular GABA-concentration also in the human brain cortex (Bockbader et al. 2010, Cai et al. 2012, Calandre et al. 2016) and, thus, have weak GABAmimetic features that most likely drive the relaxation and euphoria which are often experienced in the beginning of the gabapentinoid use or therapy and after overdoses. There is a substantial tolerance against this "euphoric high" being typical for traditional GABAmimetics, e.g. benzodiazepines or propofol (Bonnet 2011). Pharmacokinetically, the gabapentinoids are nearly "ideal" pharmaceuticals with negligible interaction potential (with the exception of combining with clozapine or opioids (Englisch et al. 2012, 
Calandre et al. 2016)), no metabolism and no protein binding (Bockbader et al. 2010, Calandre et al. 2016). However, they need a dose reduction alongside increasing renal insufficiency (Calandre et al. 2016). In comparison with propofol and benzodiazepines, gabapentinoids were the safest GABAmimetics with a wide dose range between pleasure (euphoria) and death due to overdoses. Whether an extreme oral overdose of gabapentin is sufficient enough to induce life threatening respiratory or cardiac insufficiency in otherwise healthy nonelderly subjects is still controversial (Verma et al. 1999, Batoon et al. 2001, Ongley et al. 2014). However, an excessive overdose of pregabalin may have fatal consequences if combined with opioid therapy and probably also with sedative therapy (Häkkinen et al. 2014). Fatalities in association with excessive gabapentin use alone have not yet become known, although gabapentin has been assumed to be the operative agent of two suicides (Middleton 2011, Cantrell et al. 2015). Suicides by pregabalin alone have not yet been described, but vice versa, suicidal ideations have been reported after initiating a gabapentinoid therapy (Mutschler et al. 2011) which have also been described for other anticonvulsants (Mula et al. 2013). There are further important pharmacologic differences between gabapentin and pregabalin. Firstly, gabapentin is absorbed more slowly and has a lower bioavailability $(33-66 \%$ for gabapentin vs $>90 \%$ for pregabalin). Secondly, gabapentin`s plasma concentrations have been found to have a non-linear relationship with increasing oral doses. In the case of pregabalin, the plasma concentrations increase more rapidly and linearly with increasing doses if compared with gabapentin. Thirdly, pregabalin has a stronger inhibitory action on the $\alpha_{2} \delta$-subunits containing VCGGs than gabapentin (Bockbader et al. 2010, Calandre et al. 2016).

\section{WIDE DISTRIBUTION OF GABAPENTINOIDS}

Since their introduction into the markets (gabapentin 1997, pregabalin 2004), both gabapentinoids have become blockbuster prescription drugs with meanwhile myriads of prescriptions worldwide (Kapil et al. 2014, Schwabe \& Pfaffrath 2015, Calandre et al. 2016), however, often for "off-label" use e.g. against anxiety, agitation, non-neuropathic pain, mood instability, insomnia, neurasthenia, somatoform disorders, and withdrawal symptoms from various recreational drugs (Calandre et al. 2016, Freynhagen et al. 2016). Gabapentin and pregabalin were assigned to have a considerable abuse liability since they were observed to undergo a transition from prescription drugs to recreational drugs becoming progressively obtainable via the internet or on the black market (Schifano et al. 2011, Mersfelder \& Nichols 2016, Smith et al. 2016, Schjerning et al. 2016a) in the past ten years.

\section{ANALYZING CASE REPORTS ABOUT GABAPENTINOID ADDICTION}

The authors are familiar with gabapentin prescriptions since the late 1990ies (Bonnet et al. 1999) and used gabapentin also "off-label" temporarily and beneficially over thousand times i) as an adjunct in the treatment of withdrawal symptoms due to alcohol, benzodiazepines, cannabis and opioids (Freynhagen et al. 2016) or ii) in the treatment of nervousness or agitation in anxiety and affective disorders or dementia (Bonnet \& Scherbaum 2016). Among those patients with no relation to another SUD (except for nicotine dependence), we saw 6 cases of mid-life adults and elderlies, who developed a withdrawal syndrome after several weeks of the treatment with gabapentin. These patients ( 4 females, 2 males) had been diagnosed with generalized anxiety disorder or anxious depression and had stopped the gabapentin treatment (1200-3200 mg gabapentin/day) erroneously in an abrupt manner. Upcoming withdrawal symptoms resembled those of SSRIs (Fava et al. 2015) or benzodiazepines (Tyrer et al. 1990) and comprised of agitation, dysphoria, irritability, depersonalization, gait instability, vertigo, lightheadness, dizziness, fatigue, tremor, insomnia, myalgia, flu-like symptoms, abdominal discomfort, nausea, sleeplessness, palpitations and tachycardia. The larger the gabapentin doses had been prior to abrupt quitting, the stronger was the withdrawal syndrome, which could be well mitigated by reinstating gabapentin, which was thereafter gradually tapered in the following few weeks without problems. With the exception of this withdrawal syndrome and some tolerance to gabapentin's intended beneficial action on agitation and anxiety, there were no further symptoms of SUD in these patients, especially no reward craving, no loss of control, no drug-seeking behavior or further narrowed behaviors toward this drug - all these symptoms would have been typical for behavioral (psychological) dependence (Dilling \& Freyberger 2006, Bonnet 2011). The observed physical dependence on gabapentin, in other words withdrawal symptoms and tolerance, were in line with previous reports (Smith et al. 2016, Mersfelder \& Nichols 2016).

In Pubmed and Scopus, we found 10 cases in relation to gapapentin abuse or dependence (Markowitz et al. 1997, Barrueto et al. 2002, Reccoppa et al. 2004, Victorri-Vigneau et al. 2007, Pittenger et al. 2007, Kruszewski et al. 2009, Hellweg et al. 2010, Reeves \& Burke 2014, Reeves \& Ladner 2014) and 17 cases with pregabalin abuse or dependence (Grosshans et al. 2010, Filipetto et al. 2010, Westin \& Strøm 2010, Yargic \& Ozdemiroglu 2011, Skopp \& Zimmer 2012, Carrus \& Schifano 2012, Aldemir et al. 2013, Papazisis et al. 2013, Gahr et al. 2013a, Barrett et al. 2015, Ashwini et al. 2015, Yazdi et al. 2015, Gahr et al. 2015, Halaby et al. 2015, Nordgaart \& Jürgens 2015, Driot et al. 2016). We evaluated these case 
reports according to fulfilled ICD-10 dependence criteria (Dilling \& Freyberger 2006) and found that i) tolerance and withdrawal symptoms were common in gabapentinoid dependence, and ii) unlike pregabalin $(\mathrm{N}=13)$ (Grosshans et al. 2010, Filipetto et al. 2010, Yargic \& Ozdemiroglu 2011, Skopp \& Zimmer 2012, Carrus \& Schifano 2012, Aldemir et al. 2013, Papazisis et al. 2013, Gahr et al. 2013a, Barrett et al. 2015, Yazdi et al. 2015, Gahr et al. 2015), gabapentin was rarely associated with symptoms of behavioral dependence $(\mathrm{N}=2)$ (Victorri-Vigneau et al. 2007, Kruszewski et al. 2009). Of note, the majority of the cases presenting behavioral dependence symptoms on gabapentinoids $(67 \%, 11$ out of 15 case reports) had a positive addiction history with traditional psychoactive drugs, mostly alcohol, benzodiazepines and opioids. Similar results were described in recent reviews regarding gabapentin (Smith et al. 2016, Mersfelder \& Nichols 2016) and pregabalin abuse and dependence (Schjerning et al. 2016a). There were only 4 case reports which have described symptoms of behavioral dependence on gabapentinoids and no positive addiction history (Yargic \& Ozdemiroglu 2011, Ashwini et al. 2015, Halaby et al. 2015, Driot et al. 2016). These cases may reflect the abuse potential of gabapentinoids the best and have been all related to pregabalin (Yargic \& Ozdemiroglu 2011, Ashwini et al. 2015, Halaby et al. 2015, Driot et al. 2016).

Since 2008, numerous but unspecified cases about pregabalin abuse have been reported to the European Montitoring Centre for Drugs and Drug Addiction (EMCDDA), mainly via Scandinavian, British, French and German pharmacovigilance systems, the vast majority describing patients being currently or previously dependent on other substances, too (Chalabianloo \& Schjøtt 2009, Schwan et al. 2010, Gahr et al. 2013b; Bodén et al. 2014, Asomaning et al. 2016, Schjerning et al. 2016b, Bossard et al. 2016). This association was supported by the latest analysis of the EudraVigilance database (Chiappini \& Schifano 2016) which included spontaneous reports from Europa, North and South America as well as East Asia.

\section{OTHER CLINICAL OBSERVATIONS ABOUT GABAPENTINOID ADDICTION}

In clinical populations, gabapentin misuse and overdosing was identified most often in association with opiate addiction and multiple drug using (Bastiaens et al. 2016, Wilens et al. 2015, Baird et al. 2013). In support, a prospective study in Appalachian Kentucky found a large increase of gabapentin use in the cohort of non-medical prescription opioid users, who used gabapentin specifically to get "high" (Smith et al. 2015). An amplification of a desired opioid high and relief of anxiety symptoms during opiate withdrawal were strong factors for promoting this misuse (Bastiaens et al. 2016, Wilens et al. 2015, Baird et al.
2013). Notably there are two plain case reports of psychiatric patients without a history of another SUD, who self-administrated pregabalin in large supratherapeutic amounts (1500-3000 mg/day) to stimulate themselves and produce euphoria (Halaby et al. 2015, Ashwani et al. 2015). Similar information about pregabalin misuse and overdosing is available from emergency medicine (Millar et al. 2013) and methadone maintenance treatment programs (Schifano et al. 2011, Grosshans et al. 2013, Piralishvili et al. 2013, McNamara et al. 2015). For reasons of methodology, those epidemiological studies primarily basing on drug urine screenings are as unspecific as pharmacovigilance reports to verify causality between the finding of non-medical gabapentinoid use, even in supratherapeutic doses, and true addictive behavior or hazard induced by this usage.

\section{ADDICTIVE USE OF GABAPENTINOIDS IN VARIOUS POPULATIONS}

Currently, there is no valid information about the prevalence of addictive use of gabapentinoids in the general population. Using a questionnaire basing on DSM-IV (Wittchen et al. 1997), Cossmann et al. (2016) reported a lifetime prevalence of $0.25 \%$ for gapentinoid abuse and dependence in a German geriatric non-demented hospital population (Cossmann et al. 2016). In an online survey, Kapil et al. (2014) found the following self-reported lifetime prevalences of misuse of GABA-analogues in the younger and mid-life UK population: baclofen $(1.3 \%)$, gabapentin (1.1\%), and pregabalin (0.5\%) (Kapil et al. 2014). Characteristically, these cases were linked to another substance abuse or dependence, mostly opioids again (Kapil et al. 2014, Coßmann et al. 2016). There is robust evidence that risk populations, such as multiple drug users or patients in methadone treatment programs, have selected gabapentinoids due to their special features to boost an euphoric high and reduce withdrawal symptoms (Schwan et al. 2010, Schifano et al. 2011, Grosshans et al. 2013, Baird et al. 2013, Piralishvili et al. 2013, Wilens et al. 2015, Smith et al. 2015, Bastiaens et al. 2016). These cohorts of addicts preferred pregabalin, which allows a more rapid and stronger euphoric high and relaxation than would be possible with gabapentin (Bockbader et al. 2010, Calandre et al. 2016). However, these reinforcing effects underlie rapid tolerance which promotes overdosing. At this juncture, pregabalin has been associated more closely with the hazards of these populations, such as behavioral dependence (Grosshans et al. 2010, Filipetto et al. 2010, Yargic \& Ozdemiroglu 2011, Skopp \& Zimmer 2012, Carrus \& Schifano 2012, Aldemir et al. 2013, Papazisis et al. 2013, Gahr et al. 2013, Barrett et al. 2015, Yazdi et al. 2015, Gahr et al. 2015) and even death (Häkkinen et al. 2014) in comparison with gabapentin. 


\section{LIKING AND WANTING OF GABAPENTINOIDS}

Unlike traditional psychoactive drugs, there is less, if any, evidence for gabapentinoids to be misused in a long-term manner (Smith et al. 2016, Mersfelder \& Nichols 2016, Schjerning et al. 2016b). This would support the hypothesis that gabapentinoids can induce a "liking" (euphoric high) due to their GABAmimetic action but no or only minimal "wanting" (most likely behavioral dependence) (Berridge \& Robinson 2016) which corresponds with no or only minimal rewarding properties of gabapentinoids in animal experiments (Andrews et al. 2001, Rutten et al. 2011). Non-treatment seeking cocaine abusers did not alter their choice to self-administer cocaine while on gabapentin maintenance (up to $3200 \mathrm{mg} /$ day) (Hart et al. 2007), which also did not highlight a robust addictive potency ("wanting") of gabapentinoids. There are several further nonregulated medications being deemed to have no relevant addictive potential ("wanting") and observed to be abused preferentially by patients with a history of another SUD. These include some antidepressants (tranylcypromine, bupropion, tianeptine) (Haddad 1999, Bernard et al. 2011, Costa et al. 2015), antipsychotics (quetiapine) (Montebello \& Brett 2015) or pain relievers (flupirtin) (Gahr et al. 2013c).

On this background, we do suggest that gabapentin and pregabalin belong to such substances, which themselves have no relevant addiction potency suis generis ("wanting"), but could become addictive in patients with prior SUD-experience. Those patients look for various options broadly being able to induce euphoria and to improve their affected stress reactivity that occur following substance addiction (Fosnocht \& Brand 2016). Unlike nicotine, alcohol, opiates or benzodiazepines, there is yet no evidence for gabapentinoids to facilitate the misuse of other drugs in patients without a history of SUD.

Although gabapentinoids are widely distributed, we have found only 4 cases (as mentioned above) supporting a "wanting" of gabapentinoids in patients without a history of SUD and these 4 cases refer to pregabalin and not to gabapentin (Yargic \& Ozdemiroglu 2011, Ashwini et al. 2015, Halaby et al. 2015, Driot et al. 2016). This is still below the frequency of cases having reported extremely rare clinical phenomena, such as the toxicologically relevant gut fermentation syndrome ("endogeneous auto-brewery") (Cordell \& McCarthy 2013, Welch et al. 2016). The view that pregabalin is usually not related to the development of behavioral dependence ("wanting") in populations not at risk is further supported by an analysis of the French Pharmacovigilance Database, where no significant association between exposure to pregabalin and drug abuse or dependence was found, nevertheless, taking into account the methodologic limitations of spontaneous reporting pharmacovigilance systems (Bossard et al. 2016).

\section{EVALUATING THE ADDICTIVE POWER OF GABAPENTINOIDS}

Weighting the adverse effects being published in association with gabapentin and pregabalin and considering the information about their addictive power as mentioned above, we propose Table 1 to compare the abuse potential and toxicity of gabapentinoids with those of traditional psychoactive substances. As yet, pregabalin deemed more risky to induce dependence than gabapentin. Most likely, this is primarily based upon the special pharmacokinetic feature that unlike gabapentin, the plasma (and brain) concentrations of

Table 1. Risk of dependence and hazards of gabapentinoids and traditional psychoactive substances: a comparative appraisal

\begin{tabular}{|c|c|c|c|c|c|}
\hline $\begin{array}{l}\text { Characteristics/substance } \\
\text { of abuse }\end{array}$ & Opiates & Alcohol & Gabapentin & Pregabalin & $\begin{array}{c}\text { Benzo- } \\
\text { diazepines }\end{array}$ \\
\hline $\begin{array}{l}\text { Physical dependence } \\
\text { (tolerance, withdrawal } \\
\text { symptoms }\end{array}$ & $* * * * *$ & $* * * *$ & $* * *$ & $* * *$ & $* * * *$ \\
\hline $\begin{array}{l}\text { Behavioral = psychological } \\
\text { dependence (craving, loss of } \\
\text { control, addictive behavior) }\end{array}$ & $* * * * *$ & $* * * * *$ & $\begin{array}{c}\left({ }^{*}\right) \\
\text { (in patients with } \\
\text { history of SUD) }\end{array}$ & $\begin{array}{c}* \\
\text { (especially in patients } \\
\text { with history of SUD) }\end{array}$ & $* * * *$ \\
\hline Overall toxicity & $\begin{array}{l}* * * * * \\
\text { (not in } \\
\text { therapy) }\end{array}$ & $* * * *$ & $\begin{array}{c}* * \\
\text { (especially in elderlies } \\
\text { or in overdose mixtures } \\
\text { with opioids or sedatives) }\end{array}$ & $\begin{array}{c}* * * \\
\text { (especially in elderlies } \\
\text { or in overdose mixtures } \\
\text { with opioids or sedatives) }\end{array}$ & $* * * *$ \\
\hline Social hazards & $* * * * *$ & $* * * * *$ & unknown & unknown & $* * * *$ \\
\hline
\end{tabular}

Abbreviations: SUD = Substance use disorder; $\quad$ - = no effects; $\quad *=$ very weak effects; $\quad * *=$ weak effects;

$* * *=$ moderate effects; $\quad * * * *=$ strong effects; $\quad * * * * *=$ very strong effects.

The estimation of the toxicity of gabapentinoids based upon the present review and concerning adverse effects, also on the following literature: Verma et al. 1999, Batoon et al. 2001, Sechi et al. 2004, Babiy et al. 2005, Abdennour et al. 2007, Raju et al. 2007, Tuccori et al. 2007, Ege et al. 2008, Perez Lloret et al. 2009, Fuzier et al. 2013, Prescrire Int 2014, Ongley et al. 2014, Beauvais et al. 2015, Scholl et al. 2015.Calandre et al. 2016). The toxicity of traditional drugs of abuse based upon the authors' expertise in the treatment of drug- and alcohol addiction (e.g. Bonnet et al. 1999, Bonnet and Gastpar 1999, Bonnet 2011, Scherbaum 2016). 
pregabalin increase linearly with increasing doses (Bockbader et al. 2010, Calandre et al. 2016). Phenotypically, patients reported pleasant stimulation and euphoria when using supratherapeutic pregabalin doses (1500-3000 mg) (Halaby et al. 2015, Ashwani et al. 2015, Millar et al. 2013, Grosshans et al. 2013), and in rats, conditioned place preference was induced only with higher ("supratherapeutic") intraperitoneal (but not oral) pregabalin doses (Andrews et al. 2001, Rutten et al. 2011). Yet, contrarily to gabapentin, the prescription and distribution of pregabalin is regulated by the drug and narcotics laws in the USA and Norway. Thus, it has been listed in the Drug Enforcement Administration (DEA) schedule V (USA) and schedule C (Norway), which control psychoactive drugs with the lowest risk for abuse (DEA 2005, Westin \& Strøm 2010). In Germany, prescription of gabapentinoids is hitherto not regulated by his Narcotic Drugs and Psychotropic Substances Law, just as in most other countries of the world.

\section{CONCLUSION}

Altogether, we support the view that the abuse potential of both, gabapentin and pregabalin, is of lower priority in patients without another current or past SUD. In these "abuse-history-free" patients, the treatment with gabapentinoids is advised to be managed similar to the treatment with other frequently prescribed medications. In patients with a history of SUD, however, gabapentinoids (notably pregabalin) should better to be avoided or if indispensable, administered with caution by using a strict therapeutic and prescription monitoring. This is already stated in the package inserts of gabapentinoid medications. Prospective studies comparing the frequency, pattern and course of addiction criteria (Dilling \& Freyberger 2006, APA 2013) and drug safety data alongside the gabapentinoid use or misuse of patients with and without the experience of another SUD are missing and warranted to estimate the true addictive and hazardous potency of gabapentin and pregabalin more accurately which is also recommended for the antidepressants, antipsychotics and non-opiod pain relievers being supposed to be addictive.

\section{Acknowledgements: None.}

\section{Conflict of interest: None to declare.}

\section{Contribution of individual authors:}

Conception: Udo Bonnet;

Collection, analysis and interpretation of data: Udo Bonnet, Emily-Lisa Richter, Katrin Isbruch, Norbert Scherbaum;

Drafting the article: Udo Bonnet;

Revising it critically for important intellectual content: Emily-Lisa Richter, Katrin Isbruch, Norbert Scherbaum.

\section{References}

1. Abdennour L, Sanchez-Peña P, Galanaud D, Navarro V, Weiss N, et al: Gabapentin-induced coma: a MR-spectrometry analysis. Neuropsychiatr Dis Treat 2007; 3:695-702

2. Aldemir E, Altıntoprak AE, Coşkunol H: Pregabalin Dependence: A Case Report. Turk Psikiyatri Derg 2015; 26:217-20

3. Andrews N, Loomis S, Blake R, Ferrigan L, Singh L, et al: Effect of gabapentin-like compounds on development and maintenance of morphine-induced conditioned place preference. Psychopharmacology 2001; 157:381-387

4. APA - American Psychiatric Association: Diagnostic and statistical manual of mental disorders. Fifth Edition, DSM-5TM. APA. Arlington 2013, USA

5. Ashwini S, Amit DR, Ivan NS \& Alka PV: Pregabalin dependence with pregabalin induced intentional self-harm behavior: A case report. Indian J Psychiatry 2015; 57:110-1

6. Asomaning K, Abramsky S, Liu Q, Zhou X, Sobel RE, et al: Pregabalin prescriptions in the United Kingdom: a drug utilisation study of The Health Improvement Network (THIN) primary care database. Int J Clin Pract 2016; 70:380-8

7. Babiy M, Stubblefield MD, Herklotz $M$ \& Hand M: Asterixis related to gabapentin as a cause of falls. Am J Phys Med Rehabil 2005; 84:136-40

8. Baird CR, Fox P, Colvin LA: Gabapentinoid abuse in order to potentiate the effect of methadone: a survey among substance misusers. Eur Addict Res 2013; 20:115-8

9. Barrett, JA, Kittler LM \& Singarajah C: Acute Pregabalin Withdrawal: A Case Report and Review of the Literature. Southwest Journal of Pulmonary and Critical Care 2015; 10:306-310

10. Barrueto F Jr, Green J, Howland MA, Hoffman RS \& Nelson LS: Gabapentin withdrawal presenting as status epilepticus. J Toxicol Clin Toxicol 2002; 40:925-8

11. Bastiaens L, Galus $J$ \& Mazur C: Abuse of Gabapentin is Associated with Opioid Addiction. Psychiatr $Q$ 2016; 87:763-76

12. Batoon SB, Vela AT, Dave D, Wahid Z, Conetta R, et al: Recurrent hypoventilation and respiratory failure during gabapentin therapy. J Am Geriatr Soc 2001; 49:498

13. Beauvais K, Disson-Dautriche A, Jacquin A, Antoniol C \& Martin ML: Gabapentin-induced encephalopathy. Clin Neurophysiol 2015; 126:845-6

14. Bernard K, Penelaud PF, Mocaër E \& Donazzolo Y: Absence of psychostimulant effects of a supratherapeutic dose of tianeptine: a placebo-controlled study versus methylphenidate in young healthy volunteers. J Clin Psychopharmacol 2011; 31:441-8

15. Berridge $K C$ \& Robinson TE: Liking, wanting, and the incentive-sensitization theory of addiction. Am Psychol 2016; 71:670-679

16. Bockbader HN, Wesche D, Raymond M, Chapel S, Janiczek $N$, et al: A comparison of thepharmacokinetics and pharmacodynamics of pregabalin and gabapentin. Clin Pharmacokin 2010; 49:661-669

17. Bodén R, Wettermark B, Brandt L \& Kieler H: Factors associated with pregabalin dispensing at higher than the approved maximum dose. Eur J Clin Pharmacol 2014; 70:197-204 
18. Bonnet U, Banger M, Leweke FM, Maschke M, Kowalski $T$ \& Gastpar: Treatment of alcohol withdrawal syndrome with gabapentin. Pharmacopsychiatry 1999; 32:107-9

19. Bonnet U \& Gastpar M: Kapitel 21: Opioide. In Gastpar M, Mann K, Hans Rommelspacher H (Eds): Lehrbuch der Suchterkrankungen: Thieme, Stuttgart, Germany 1999; pp. 237-262. [Articel in German]

20. Bonnet U: Einschätzung des Abhängigkeitsrisikos von Propofol. Fortschr Neurol Psychiatr 2011; 79:442-52. [Articel in German]

21. Bonnet U \& Scherbaum N: Comment: Gabapentin: Abuse, Dependence, and Withdrawal. Ann Pharmacother 2016; 50:691

22. Bossard JB, Ponté C, Dupouy J, Lapeyre-Mestre $M$ \& Jouanjus E: Disproportionality Analysis for the Assessment of Abuse and Dependence Potential of Pregabalin in the French Pharmacovigilance Database. Clin Drug Investig 2016; 36:735-42

23. Cai K, Nanga RP, Lamprou L, Schinstine C, Elliott M, Hariharan $H$, et al: The impact of gabapentin administration on brain GABA and glutamate concentrations: a $7 T{ }^{1} H$-MRS study. Neuropsychopharmacology 2012; $37: 2764-71$

24. Calandre EP, Rico-Villademoros F\& Slim M: Alphazdelta ligands, gabapentin, pregabalin and mirogabalin: a review of their clinical pharmacology and therapeutic use. Expert Rev Neurother 2016; 16:1263-1277

25. Cantrell FL, Mena O, Gary RD \& McIntyre IM: An acute gabapentin fatality: a case report with postmortem concentrations. Int J Legal Med 2015; 129:771-5

26. Carrus D \& Schifano F: Pregabalin misuse-related issues; intake of large dosages, drug-smoking allegations, and possible association with myositis: two case reports. $J$ Clin Psychopharmacol 2012; 32:839-40

27. Chalabianloo $F \&$ Schjøtt J: [Pregabalin and its potential for abuse]. Tidsskr Nor Laegeforen 2009; 129:186-7. [Article in Norwegian]

28. Chiappini $S$ \& Schifano F: A Decade of Gabapentinoid Misuse: An Analysis of the European Medicines Agency's 'Suspected Adverse Drug Reactions' Database. CNS Drugs 2016; 30:647-54

29. Cordell B \& McCarthy J: A Case Study of Gut Fermentation Syndrome (Auto-Brewery) with Saccharomyces cerevisiae as the Causative Organism. Int J Clin Med 2013; 4:309-312

30. Cossmann JC, Scherbaum $N$ \& Bonnet U: Substance addiction in old age: A cross-sectional study in a German Hospital. GeroPsych: The Journal of Gerontopsychology and Geriatric Psychiatry 2016; $29: 17-27$

31. Costa C, Araujo A, Brasil M \& Cruz M: Possible addiction transference from cocaine insufflation to oral bupropion in bipolar patient. J Addict Med 2015; 9:1 55-6

32. DEA - Drug Enforcement Administration, Department of Justice: Schedules of controlled substances: placement of pregabalin into schedule V. Final rule. Fed Regist 2005; 70:43633-5

33. Dilling $H \&$ \&reyberger HJ: Taschenführer zur ICD-10Klassifikation psychischer Störungen. Bern: Hans Huber Verlag, 2006

34. Dooley DJ, Donovan CM \& Pugsley TA: Stimulusdependent modulation of [(3)H]norepinephrine release from rat neocortical slices by gabapentin and pregabalin. J Pharmacol Exp Ther 2000; 295:1086-93
35. Driot D, Chicoulaa B, Jouanjus E, Dupouy J, Oustric S \& Lapeyre-Mestre M: Pregabalin use disorder and secondary nicotine dependence in a woman with no substance abuse history. Therapie 2016; 71:575-578. [Articel in French]

36. Ege F, Koçak Y, Titiz AP, Oztürk SM, Oztürk $S$ \& Ozbakir S: Gabapentin-Induced myoclonus: case report. Mov Disord 2008; 23:1947-8

37. Englisch $S$, Alm B, Meyer-Lindenberg $A$ \& Zink M: Pregabalin-associated increase of clozapine serum levels. J Clin Psychopharmacol 2012; 32:127

38. Eroglu C, Allen NJ, Susman MW, O'Rourke NA, Park CY, Ozkan E, et al: Gabapentin receptor alpha2delta-1 is a neuronal thrombospondin receptor responsible for excitatory CNS synaptogenesis. Cell 2009; 139:380-92

39. Fava GA, Gatti A, Belaise C, Guidi $J$ \& Offidani E: Withdrawal Symptoms after Selective Serotonin Reuptake Inhibitor Discontinuation: A Systematic Review Psychother Psychosom 2015; 84:72-81

40. Filipetto FA, Zipp CP \& Coren JS: Potential for pregabalin abuse or diversion after past drug-seeking behavior. J Am Osteopath Assoc 2010; 110:605-7

41. Fosnocht $A Q$ \& Briand LA: Substance use modulates stress reactivity: Behavioral and physiological outcomes. Physiol Behav 2016; 166:32-42

42. Freynhagen R, Backonja M, Schug S, Lyndon G, Parsons $B$, Watt S, et al: Pregabalin for the Treatment of Drug and Alcohol Withdrawal Symptoms: A Comprehensive Review. CNS Drugs 2016; 30:1191-1200

43. Fuzier R, Serres I, Guitton E, Lapeyre-Mestre $M$ \& Montastruc JL: French Network of Pharmacovigilance Centres: Adverse drug reactions to gabapentin and pregabalin: a review of the French pharmacovigilance database. Drug Saf 2013; 36:55-62

44. Gahr M, Franke B, Freudenmann RW, Kölle MA \& Schönfeldt-Lecuona $C$ : Concerns about pregabalin: further experience with its potential of causing addictive behaviors. J Addict Med 2013a; 7:147-9

45. Gahr M, Freudenmann $R W$, Hiemke C, Kölle MA \& Schönfeldt-Lecuona C: Pregabalin abuse and dependence in Germany: results from a database query. Eur J Clin Pharmacol 2013b; 69:1335-42

46. Gahr M, Freudenmann RW, Connemann BJ, Hiemke $C$ \& Schönfeldt-Lecuona $C$ : Abuse liability of flupirtine revisited: implications of spontaneous reports of adverse drug reactions. J Clin Pharmacol 2013c; 53:1328-33

47. Gahr M, Freudenmann RW, Kölle MA \& SchönfeldtLecuona C: From benzodiazepine to pregabalin dependence: Different agents, similar problems. Ind J Psychiat 2015; 57:111-2

48. Grosshans M, Mutschler J, Hermann D, Klein O, Dressing $H$, Kiefer F, et al: Pregabalin abuse, dependence, and withdrawal: A case report. Am J Psychiatry 2010; 167:869

49. Grosshans M, Lemenager T, Vollmert C, Kaemmerer N, Schreiner R, Mutschler J, et al: Pregabalin abuse among opiate addicted patients. Eur J Clin Pharmacol 2013; 69:2021-5

50. Haddad P: Do antidepressants have any potential to cause addiction? J Psychopharmacol 1999; 13:300-7

51. Häkkinen M, Vuori E, Kalso E, Gergov M \& Ojanperä I: Profiles of pregabalin and gabapentin abuse by postmortem toxicology. Forensic Sci Int 2014; 241:1-6

52. Halaby A, Kassm SA \& Naja WJ: Pregabalin dependence: a case report. Curr Drug Saf 2015; 10:184-6 
53. Hart CL, Haney M, Vosburg SK, Rubin E \& Foltin RW: Gabapentin does not reduce smoked cocaine self-administration: employment of a novel self-administration procedure. Behav Pharmacol 2007; 18:71-5

54. Hellwig TR, Hammerquist $R$ \& Termaat J: Withdrawal symptoms after gabapentin discontinuation. Am J Health Syst Pharm 2010; 67:910-2

55. Iorio ML, Moretti U, Colcera S, Magro L, Meneghelli I, Motola D, et al: Use and safety profile of antiepileptic drugs in Italy. Eur J Clin Pharmacol 2007; 63:409-15

56. Kapil V, Green JL, Le Lait MC, Wood DM \& Dargan PI: Misuse of the $\gamma$-aminobutyric acid analogues baclofen, gabapentin and pregabalin in the UK. Br J Clin Pharmacol 2014; 78:190-1

57. Kruszewski SP, Paczynski RP \& Kahn DA: Gabapentin-induced delirium and dependence. Psychiatr Pract 2009; 15:314-9

58. Markowitz JS, Finkenbine R, Myrick H, King L \& Carson WH: Gabapentin abuse in a cocaine user: implications for treatment? J Clin Psychopharmacol 1997; 17:423-4

59. McNamara S, Stokes $S$, Kilduff $R \&$ Shine A: Pregabalin Abuse amongst Opioid Substitution Treatment Patients. Ir Med J 2015; 108:309-10

60. Mersfelder TL \& Nichols WH: Gabapentin: Abuse, Dependence, and Withdrawal. Ann Pharmacother 2016; 50:229-33

61. Middleton O: Suicide by Gabapentin overdose, J Forensic Sci 2011; 56:1373-1375

62. Millar J, Sadasivan $S$, Weatherup $N$ \& Lutton S: Lyrika nights - recreational pregabalin abuse in an urban emergency department. Emerg Med J 2013; 30:874

63. Montebello ME \& Brett J: Misuse and Associated Harms of Quetiapine and Other Atypical Antipsychotics. Curr Top Behav Neurosci 2015; [Epub ahead of print]

64. Mula M, Kanner AM, Schmitz B \& Schachter S: Antiepileptic drugs and suicidality: An expert consensus statement from the Task Force on Therapeutic Strategies of the ILAE Commission on Neuropsychobiology. Epilepsia 2013; 54:199-203

65. Mutschler J, Grosshans M, Herwig U, Heekeren K, Kawohl W \& Brühl A: Pregabalin-induced suicidal ideations. Pharmacopsychiatry 2011; 44:119

66. Nordgaard J, Jürgens G: [Pregabalin can cause addiction and withdrawal symptoms]. Ugeskr Laeger 2015; 177:389. [Article in Danish]

67. Ongley D, Hayward AK\& Allan C: Severe respiratory depression associated with perioperative opioid-sparing gabapentin use. Anaesth Intensive Care 2014; 42:136-7

68. Papazisis G, Garyfallos G, Sardeli C\& Kouvelas D: Pregabalin abuse after past substance-seeking behavior. Int J Clin Pharmacol Ther 2013; 51:441-2

69. Perez Lloret S, Amaya M \& Merello M: Pregabalin-induced parkinsonism: A case report. Clin Neuropharmacol 2009; 32:353-4

70. Pittenger $C \&$ Desan PH: Gabapentin abuse, and delirium tremens upon gabapentin withdrawal. J Clin Psychiatry 2007; 68:483

71. Piralishvili G, Gamkrelidze I, Nikolaishvili $N$ \& Chavchanidze M: Needs assessment and treatment compliance at state opioid substitution treatment programes in Georgia. Georgian Med News 2013; 214:28-32

72. Prescrire Int 2014 [no authors listed]: Gabapentin and pregabalin: hepatic and haematological toxicity. Prescrire Int 2014; $23: 267$
73. Raju PM, Walker RW \& Lee MA: Dyskinesia induced by gabapentin in idiopathic Parkinson's disease. Mov Disord 2007; 22:288-9

74. Reccoppa L, Malcolm $R \&$ Ware M: Gabapentin abuse in inmates with prior history of cocaine dependence. Am J Addict 2004; 13:321-3

75. Reeves RR \& Burke RS: Abuse of combinations of gabapentin and quetiapine. Prim Care Companion CNS Disord 2014; 11:16

76. Reeves RR \& Ladner ME: Potentiation of the effect of buprenorphine/naloxone with gabapentin or quetiapine. Am J Psychiatry 2014; 171:691

77. Rogawski MA \& Bazil CW: New molecular targets for antiepileptic drugs: alpha(2)delta, SV2A, and $K(v) 7 / K C N Q / M$ potassium channels. Curr Neurol Neurosci Rep 2008; 8:345-52

78. Rutten K, De Vry J, Robens A, Tzschentke TM \& van der Kam EL: Dissociation of rewarding, anti-aversive and anti-nociceptive effects of different classes of antinociceptives in the rat. Eur J Pain 2011; 15:299-305

79. Scherbaum N: Das Drogentaschenbuch. Thieme 2016, Stuttgart, Germany. [Articel in German]

80. Schifano F, D'Offizi S, Piccione M, Corazza O, Deluca P, Davey $Z$, et al: Is there a recreational misuse potential for pregabalin? Analysis of anecdotal online reports in comparison with related gabapentin and clonazepam data. Psychother Psychosom 2011; 80:118-22

81. Schjerning $O$, Rosenzweig $M$, Pottegård A, Damkier $P$ \& Nielsen J: Abuse Potential of Pregabalin: A Systematic Review. CNS Drugs 2016a; 30:9-25

82. Schjerning $O$, Pottegård A, Damkier P, Rosenzweig $M$ \& Nielsen J: Use of Pregabalin - A Nationwide Pharmacoepidemiological Drug Utilization Study with Focus on Abuse Potential. Pharmacopsychiatry 2016b; 49:155-61

83. Sechi G, Murgia B, Sau G, Peddone L, Tirotto A, Barrocu $M$, et al: Asterixis and toxic encephalopathy induced by gabapentin. Prog Neuropsychopharmacol Biol Psychiatry 2004; 28:195-9

84. Scholl JH, van Eekeren $R \&$ van Puijenbroek EP: Six cases of (severe) hypoglycaemia associated with gabapentin use in both diabetic and non-diabetic patients. $\mathrm{Br} J$ Clin Pharmacol 2015; 79:870-1

85. Schwabe U \& Paffrath D (Hrsg.): ArzneiverordnungsReport 2015. Aktuelle Zahlen, Kosten, Trends und Kommentare. Springer-Verlag, Berlin 2015, Deutschland

86. Schwan S, Sundström A, Stjernberg E, Hallberg E \& Hallberg P: A signal for abuse potential for pregabalinresults from the Swedish spontaneous adverse reaction reporting system. Eur J Clin Pharmacol 2010; 66:947953

87. Skopp G \& Zimmer G. Pregabalin - ein Arzneistoff mit Missbrauchspotential? Arch Kriminol 2012; 229:44-54. [Articel in German]

88. Smith RV, Lofwall MR \& Havens JR: Abuse and diversion of gabapentin among nonmedical prescription opioid users in Appalachian Kentucky. Am J Psychiatry 2015; 172:487-8

89. Smith RV, Havens JR \& Walsh SL: Gabapentin misuse, abuse and diversion: a systematic review. Addiction 2016; 111:1160-74

90. Tuccori M, Lombardo G, Lapi F, Vannacci A, Blandizzi C \& Del Tacca M: Gabapentin-induced severe myopathy. Ann Pharmacother 2007: 41:1301-5 
91. Tyrer P, Murphy S \& Riley P: The Benzodiazepine Withdrawal Symptom Questionnaire. J Affect Disord 1990; 19:53-61

92. Verma A, St Clair EW \& Radtke RA: A case of sustained massive gabapentin overdose without serious side effects. Ther Drug Monit 1999; 21:615-7

93. Victorri-Vigneau C, Guerlais $M$ \& Jolliet P: Abuse, dependency and withdrawal with gabapentin: a first case report. Pharmacopsychiatry 2007; 40:43-4

94. Welch BT, Coelho Prabhu N, Walkoff L \& Trenkner SW: Auto-brewery Syndrome in the Setting of Long-standing Crohn's Disease: A Case Report and Review of the Literature. J Crohns Colitis 2016; 10:1448-1450

95. Westin AA \& Strøm EJ: [Yes, pregabalin can be abused!]. Tidsskr Nor Laegeforen 2010; 130:2108. [Articel in Norwegian]
96. Wilens T, Zulauf C, Ryland D, Carrellas $N \&$ CatalinaWellington I: Prescription medication misuse among opioid dependent patients seeking inpatient detoxification. Am J Addict 2015; 24:173-7

97. Wittchen H-U, Wunderlich U, Gruschwitz $S$ \& Zaudig M: SKID-I - Strukturiertes Klinisches Interview für DSM-IV. Achse I: Psychische Störungen. Interviewheft. Göttingen 1997: Hogrefe

98. Yargic I \& Ozdemiroglu FA: Pregabalin Abuse: A Case Report. Bulletin of Clinical Psychopharmacology 2011; 21:64-66

99. Yazdi K, Hemetsberger U \& Baier C: Pregabalin abuse of benzodiazepine and alcohol addicted patient. Psychiatr Danub 2015; 27:278-9

\section{Correspondence:}

Prof. Udo Bonnet, MD, PhD

Department of Psychiatry, Psychotherapy, and Psychosomatic Medicine,

Evangelisches Krankenhaus Castrop-Rauxel

Grutholzallee 21, D-44577 Castrop-Rauxel, Germany

E-mail: udo.bonnet@uni-due.de 